\title{
Burden, Drivers, and Impacts of Poor Mental Health in Young People of West and Central Africa: Implications for Research and Programming
}

\author{
Kenneth Juma, Frederick Murunga Wekesah, \\ Caroline W. Kabiru, and Chimaraoke O. Izugbara
}

K. Juma $(\bowtie)$

African Population and Health Research Center, Nairobi, Kenya

e-mail: kjuma@aphrc.org

F. M. Wekesah

African Population and Health Research Center, Nairobi, Kenya

Julius Center for Health Sciences and Primary Care,

University Medical Center Utrecht, Utrecht University, Utrecht, The Netherlands e-mail: fwekesah@aphrc.org

C. W. Kabiru

Population Council, Nairobi, Kenya

e-mail: ckabiru@popcouncil.org

C. O. Izugbara

International Center for Research on Women, Washington, DC, USA

e-mail: cizugbara@icrw.org

(C) The Author(s) 2020

M. L. McLean (ed.), West African Youth Challenges and

Opportunity Pathways, Gender and Cultural Studies in Africa and the Diaspora, https://doi.org/10.1007/978-3-030-21092-2_11 


\section{INTRODUCTION}

Mental disorders are a leading cause of disability in young people globally (Charlson et al., 2014; Mokdad et al., 2016). As many as 20\% of the world's young people (aged between 10 and 24 years) suffer a neuropsychiatric condition (Belfer, 2008), including common disorders like depression and anxiety, or severe forms like psychosis, schizophrenia, and bipolar disorder, as well as alcohol and substance dependence (Remschmidt \& Belfer, 2005). Individuals suffering from these disorders have higher mortality risks than the general population (Chesney, Goodwin, \& Fazel, 2014). While the onset of most mental disorders occurs during youth (age 12 to 24 years), few disorders are diagnosed or treated in this period (Remschmidt \& Belfer, 2005). These conditions often persist for a long time, severely disrupting young people's access to livelihoods, health care, and education, and exposing them to stigma, isolation, discrimination, and human rights abuses (Sartorius, 2007; Tarter, 2002; Tims et al., 2002). While mental disorders are commonly known for their impact on health and well-being, they are also associated with severe economic losses due to high cost of treatment and impaired ability to work, especially among young people (Esan, Kola, \& Gureje, 2012). Inadequate documentation and characterization of young people's mental health problems hampers planning and appropriate provision of services in most low- and middle-income countries (LMICs) (Jacob et al., 2007).

West and Central Africa (WCA) is one of the youngest subregions of the world (Izugbara et al., 2017). Young people make up more than onethird of the population of the subregion. WCA is also the only subregion of the world where the population of young people is projected to continue growing over the next decade (Ngom, 2017). Key risk factors for mental illness - such as civil conflicts and political instability, poverty, underemployment and unemployment, substance abuse, and human immunodeficiency virus (HIV)/AIDS-are prevalent in the subregion (Betancourt, McBain, Newnham, \& Brennan, 2013; Pacione, Measham, \& Rousseau, 2013; Sharma, Fine, Brennan, \& Betancourt, 2017; United Nations International Children's Emergency Fund [UNICEF] and Overseas Development Institute [ODI], 2009). Nevertheless, data on young people's mental and substance use disorders in WCA are limited. A few studies conducted using small, nonrepresentative samples suggest a high burden of child and adolescent mental, neurological, and substance use disorders across several countries in the subregion (Abiodun, 1992; Asare \& Danquah, 2016; Cortina, Sodha, Fazel, \& Ramchandani, 2012; Ngasa et al., 2017; Nwagu, 2016; Tunde-Ayinmode, Adegunloye, 
Ayinmode, \& Abiodun, 2012; World Health Organization [WHO], 2011; Yoder, Tol, Reis, \& de Jong, 2016). Compared to Africa's other subregions, WCA is projected to experience some of the largest increases in burden of mental and substance use disorders (i.e., Central Africa [196\%] and West Africa [129\%] compared to Southern Africa [28\%] and East Africa [139\%]) by 2050 (Charlson, Diminic, Lund, Degenhardt, \& Whiteford, 2014), with a significant proportion occurring among young individuals (Cortina et al., 2012). There are, therefore, increasing calls for WCA governments to prioritize the provision of accessible and quality mental health services to their citizens (Abdulmalik et al., 2014; Daar et al., 2014; Kleintjes, Lund, \& Flisher, 2010; Semrau et al., 2015).

Arguably, the majority of WCA countries share similar mental health profiles (Abdulmalik et al., 2014). Most of these countries have low policy priority for mental health, with acute funding gaps and inadequate human resources for mental health, widespread misconception about mental health issues, stigmatization, and human rights abuses (Gureje, Lasebikan, EphraimOluwanuga, Olley, \& Kola, 2005; Oshodi et al., 2014; Read, Adiibokah, \& Nyame, 2009; Saraceno et al., 2007). Therefore, a large "treatment gap" for mental illness exists - over $90 \%$ of people with mental illness in LMICs, including in the WCA, are untreated compared to between $44 \%$ and $70 \%$ in high-income countries (HICs) (Wang et al., 2007). For instance, a review of community-based psychiatric epidemiology studies showed that only $5.9 \%$ of young adult Jews in Israel with schizophrenia remained untreated, while the rate in New Zealand in a population of 21 -year-olds was 61.5\% (Kohn, Saxena, Levav, \& Saraceno, 2004). Ironically, this huge gap exists despite considerable evidence that, even within resource-limited countries, cost-effective strategies, such as medications and psychosocial interventions, are available and effective for most mental illnesses (Barry, Clarke, Jenkins, \& Patel, 2013; Gureje, Chisholm, Kola, Lasebikan, \& Saxena, 2007).

Whereas in HICs there is increasing recognition of mental health problems in young people and their associated impairments and comorbidities, in WCA, the mental health concerns of young people remain neglected, misunderstood, and under-researched (Atilola, Ayinde, Emedoh, \& Oladimeji, 2014; Kleintjes et al., 2010). Consequently, there is limited understanding of the burden, drivers, and impact of adolescent mental health in the WCA subregion and of the gaps in research and program implementation. This chapter summarizes existing knowledge on mental health among young people in the subregion. It highlights the burden, drivers, and impact of poor mental health among the subregion's young people. We also discuss available interven- 
tions aimed at improving mental health among these young people and draw attention to gaps in knowledge and programming as well as challenges that get in the way of promoting mental health in WCA. Findings of this study can inform policy-making as well as the design and delivery of programs related to young people's mental health and well-being.

This chapter draws on insights from relevant peer-reviewed and gray literature on mental and substance abuse disorders among young people in WCA. Mental disorders were defined according to the Diagnostic and Statistical Manual of Mental Disorders (DSM) (American Psychiatric Association [APA], 2000) and the International Classification of Diseases (ICD) (World Health Organization, 1992). We utilized the World Health Organization Assessment Instrument for Mental Health Systems (WHOAIMS) (only available for Benin, Ghana, and Nigeria) as well as reports from the Ministries of Health to describe the mental health systems available for young people. WHO-AIMS reports on the status of mental health systems in LMICs based on six domains: policy and legislative framework, mental health services, mental health in primary care, human resources, public information and links with other sectors, and monitoring and research. This chapter focuses on the mental health services domain only.

\section{Burden of Mental and Substance Use Disorders in Young People of WCA}

\section{Sources of Data for Mental Disorders Among Young People in WCA}

There is very limited coverage of representative prevalence data on mental disorders in children and adolescents in WCA. Coverage refers to the proportion of the target population (aged 10 to 24 years) represented by the available data. Virtually no country in sub-Saharan Africa (SSA), including the WCA subregion, has more than $2 \%$ coverage for any disorder (Erskine et al., 2017). So far, only Nigeria has conducted a WHO survey of Mental Health and Well-Being to assess the lifetime and 12-month prevalence of mental disorders (Gureje, Lasebikan, Kola, \& Makanjuola, 2018). In the absence of large-scale epidemiological surveys on mental disorders, most prevalence data are a product of cross-sectional community-based or clinic-based surveys, which have quality challenges arising from the use of different mental health assessment tools (e.g., screening questionnaires 
and clinical diagnostic instruments). Other key sources of reliable data include the WHO 2015 country estimates for prevalence and burden of depression and anxiety disorders (not reported by age groups), and a systematic review of the Global Burden of Disease (GBD) Study 2013 (Ferrari et al., 2013) and 2016 (Charlson, Baxter, et al., 2014).

\section{Burden of Mental Disorders Among Young People in WCA}

Some of the most common child and adolescent psychiatric disorders worldwide include anxiety disorders, depressive disorders, conduct disorders and delinquency, learning disabilities, and mental retardation (Cortina et al., 2012). In the context of WCA, a systematic review by Cortina et al. (2012) found that between $12 \%$ and $30 \%$ of children and young people aged 5 to 24 years had mental health problems. Community-based epidemiological studies in various WCA countries have estimated varied degrees of prevalence for different types of mental disorders as shown in Table 11.1. In addition, variations exist across gender. For instance, anxiety and mood disorders are known to affect boys and girls more or less equally, but adolescent girls are much more vulnerable to depression than boys (Bradley, 2001).

Mental disorders are also known to be highly disabling. In the WCA subregion, depressive disorders are among the largest contributors to years lived with disability (YLDs) for both sexes of young people aged 15 to 24 years, even though these disorders affect females more than males in all age groups (Mokdad et al., 2016), and vary by region and country (Institute for Health Metrics and Evaluation, 2017). Among young people, early onset of depressive and anxiety disorders predicts other indirect consequences such as low educational attainment, and consequently lower income, poverty, and noncommunicable diseases (NCDs), such as cardiovascular diseases. A study in Nigeria, for example, showed that child psychiatric disorders are associated with various impairments, reduced functionality, physical illness, premature mortality, and increased inequality in access to economic opportunity (Tunde-Ayinmode et al., 2012).

Poor mental health increases health expenditures and rates of health care utilization, (Charlson, Diminic, et al., 2014), which may in turn act as a barrier to mental health service uptake, as was observed in Nigeria (Jack-Ide \& Uys, 2013). Additional highlights from a Nigerian study indicate that the cost of antipsychotic medicines alone accounts for more than 


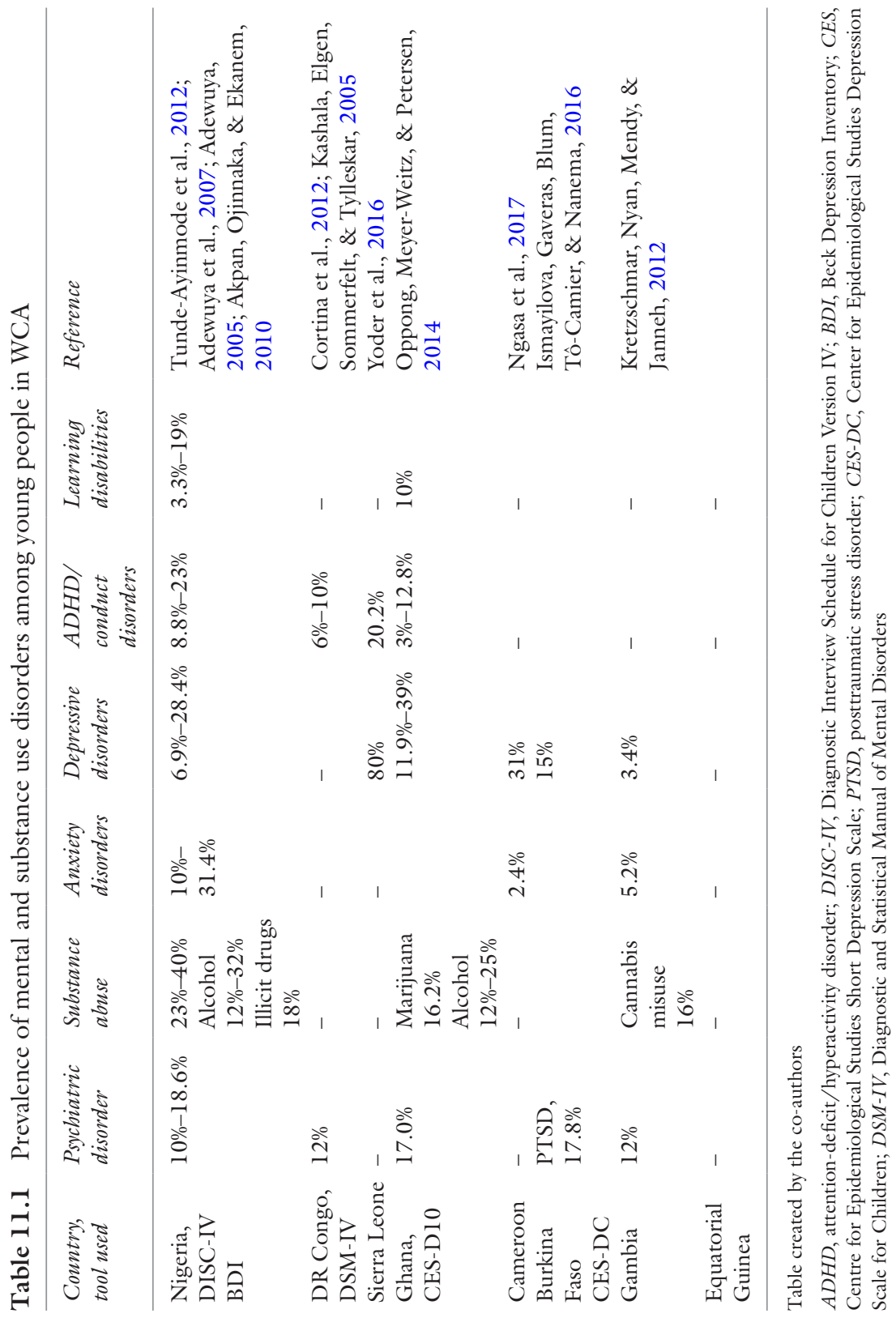


$50 \%$ of the cost of treating schizophrenia (Suleiman, Ohaeri, Lawal, Haruna, \& Orija, 1997). Also, out-of-pocket expenditures for child mental health services are $71.4 \%$ in African countries compared to $12.5 \%$ in Europe (Belfer, 2008). A study by the World Economic Forum and the Harvard School of Public Health predicted that over the next two decades, mental illness will account for the largest proportion (35\%) of global economic losses from NCDs; in absolute terms, this means that the economic toll of mental illness will be over $\$ 16$ trillion globally and $\$ 7.3$ trillion in LMICs by 2030 (Bloom et al., 2011).

\section{Substance Use Disorders Among Young People in WCA}

The types and prevalence rates of substances used vary remarkably according to context and geographical location (e.g., youths in HICs usually use injecting drugs and other substances not commonly used by adolescents from LMICs) (Embleton, Mwangi, Vreeman, Ayuku, \& Braitstein, 2013). Igwe, Ngozi, Ejiofor, Emechebe, and Ibe (2009) reported that $33.7 \%$ of 860 senior secondary school adolescents in Enugu (Nigeria) were involved in psychoactive substance abuse, while $32 \%$ and $4.1 \%$ of these adolescents had abused alcohol and used cannabis, respectively (Igwe et al., 2009). Similarly, Kayembe et al. (2008) found that $82 \%$ of street children in the Democratic Republic of Congo used marijuana, 63.5\% used alcohol, and $3.8 \%$ used cocaine (Kayembe et al., 2008). Across the WCA subregion, similar or higher prevalence levels of substance abuse among senior secondary school adolescents have been reported, including in Ghana (Addo, Mainoo, Dapaah, \& Babayara, 2016; Peltzer \& Pengpid, 2018).

The use of illicit drugs and psychoactive substance abuse among young people is associated with severe outcomes. For instance, studies in Nigeria (among students) and in Ghana (among homeless youth) found that alcohol and substance use is associated with an increased likelihood of risky sexual behavior, with accompanied increased risk for sexually transmitted infections including HIV (Nwagu, 2016; Oppong et al., 2014). While circumstances on the street may render children and youth vulnerable to various kinds of psychological problems and health risks (Burns, Daileader, \& Finger, 2004), street children using drugs and psychoactive substances are more likely to engage in crime and interpersonal violence and are also more likely to suffer traffic accidents (Doran, Luczak, Bekman, Koutsenok, \& Brown, 2012). 


\section{Drivers of Mental and Substance Use Disorders in Young People of WCA}

Adversities in early life are associated with increased risk of mental and substance use disorders (Kabiru, Beguy, Crichton, \& Ezeh, 2010). Household and family conditions and quality of parenting also have a significant impact on risk of mental and physical health (Omigbodun, 2004). Notably, key contributors to poor mental health are broadly grouped under biological factors (e.g., age and sex), social factors (e.g., relationships with caregivers during childhood), and structural factors (e.g., poverty, urbanization, change, conflict, and natural disasters) (Allen, Balfour, Bell, \& Marmot, 2014). While it is challenging to identify specific elements responsible for the onset and continuity of mental health problems, a complex interrelationship of risk factors and co-occurrence of factors exist.

In WCA, poverty is rife, as are other risk factors for mental disorders including unemployment, low incomes, poor housing, food insecurity, and low education status (Lund et al., 2010). In Nigeria, Omigbodun (2004) found that more than $50 \%$ of children at a psychiatric clinic suffering from various psychosocial stressors had experienced problems with primary support, such as separation from parents, disruption of the family, abandonment by their mother, psychiatric illness in a parent, and sexual/ physical abuse in the year preceding the study. Likewise, civil conflicts, warfare, and disease have all been identified as vulnerabilities and risk factors to child and adolescent mental health in the WCA subregion (Gupta \& Zimmer, 2018; Lokuge et al., 2013). Other common events during armed conflicts include sexual violence (sexual assault and rape), and the most common disorder in such settings is posttraumatic stress disorder (PTSD).

In recent years, the WCA subregion has experienced increased internal and regional displacement of people. According to UNICEF (2017b), over seven million children are on the move in West and Central Africa each year, mainly because of violence, poverty, and climate change and drought in countries such as the Central African Republic, Côte d'Ivoire, Liberia, Mali, Chad, Nigeria, and Sierra Leone. Unaccompanied migrant children are common among refugee populations, and these young children are often at increased risk of abuse, exploitation, or trafficking (UNICEF, 2017a). Studies have found that challenges of adjustment after migration in an often hostile context, history of family separation after 
migration, discriminatory experiences, as well as other postmigration adaptation issues (e.g., unemployment) are independently associated with depression and posttraumatic stress among migrants, who suffer from a significant burden of mental distress (Thela, Tomita, Maharaj, Mhlongo, \& Burns, 2017).

A study in the Democratic Republic of Congo reported that children exposed to armed conflict presented with anxiety-related complaints (including symptoms such as stress, worry, and fear), as well as moodrelated, behavior-related, and somatization problems (Lokuge et al., 2013). Moreover, in Sierra Leone, which experienced years of civil conflict, more than 7000 children were recruited as child soldiers and participated as spies, sex slaves, porters, and frontline soldiers, among other roles (Coalition to Stop the Use of Child Soldiers, 2008). Child soldiers were not only involved in the perpetration of violence but they were also often subjected to repeated physical, sexual, and emotional violence (Betancourt, Newnham, McBain, \& Brennan, 2018). Betancourt et al. (2010) conducted a two-year study that followed up with former child soldiers and found increased hostility in these individuals. Similarly, youths who survived rape experienced higher levels of anxiety and aggressive behaviors but also demonstrated greater confidence and prosocial attitudes at follow-up (Betancourt et al., 2010). Children in WCA who experienced other war-related atrocities have been shown to have elevated levels of emotional distress and traumatic stress symptoms, as well as persistent bad dreams, nightmares, and intense arousal symptoms (Yoder et al., 2016). Other drivers of early mental health problems include high demands of academic performance on school children (Asare \& Danquah, 2016), rapid social change and migration, social isolation, unemployment and poverty, increasing social pressures to perform well, peer pressure, individual and family crises, changes in traditional values, and conflict with parents (Burns, 2012).

Many countries in WCA have a generalized human immunodeficiency virus (HIV) epidemic (i.e., overall prevalence is 2.2\% [6.1 million], with wide variation between countries, ranging from $0.5 \%$ in Niger and Senegal to $4.9 \%$ in Equatorial Guinea). The epidemic also left many children orphaned or infected in the subregion. More than 25\% of children aged 0-14 years living with HIV worldwide are in the WCA subregion (Joint United Nations Programme on HIV/AIDS [UNAIDS] and UNICEF, 2016). A study in Ghana showed that orphaned or HIV-infected children suffer poor physical and mental functioning and sometimes live in isolation. 
Consequently, these children may develop neuropsychological dysfunction, including dementia, depression, and other disorders, which go largely untreated and lead to increased morbidity (Doku, 2016). While risk factors for mental problems in infancy and early childhood have not been widely studied, this period is the time for maximum brain growth and of formation of emotional regulatory patterns that affect later mental health outcomes (Klitzing, Döhnert, Kroll, \& Grube, 2015).

\section{Impacts of Mental and Substance Use Disorders in Young People of WCA}

In the absence of any psychosocial or pharmacologic intervention to prevent or treat mental disorders, benign mental health problems among young people in Ghana and Nigeria have been shown to degenerate into grave and costly conditions, as well as social problems such as school failure, delinquency, and substance misuse (Igwe et al., 2009; Nwagu, 2016; Oppong et al., 2014; Warner \& White, 2003). Poor mental health has also been associated with teenage pregnancy, HIV/AIDS, other sexually transmitted infections, interpersonal violence, child abuse, motor vehicle crashes, crime, homicide, and suicide (Doku, 2016; Doran et al., 2012; Nwagu, 2016). In addition, mental disorders are known to perpetuate a negative cycle of poverty, social exclusion, and reduced productivity, impacting the victim's family and the broader community (Lund et al., $2010,2011)$. Even with limited documentation of the impact of mental health disorders in young people of WCA, the few existing studies provide insights on trajectories for a range of mental disorders that young people experience. For instance, a recent GBD report showed that of the top ten causes of death and disability in young people, suicide and self-harm (a likely presentation of mental health problems) are leading causes of mortality among females and males aged 10 to 24 years (Mars, Burrows, Hjelmeland, \& Gunnell, 2014), and 75\% of global suicide deaths are in LMICs (McKinnon, Gariepy, Sentenac, \& Elgar, 2016), while at the same time alcohol and drug use (also associated with mental disorders) are leading risk factors for disability-adjusted life years (DALYS) (Mokdad et al., 2016).

In the Democratic Republic of Congo, researchers concluded that mental disorders impaired school-going children's social and educational capacities thereby affecting their school performance (Kashala et al., 
2005), while in Nigeria, adolescents with higher levels of depressive symptoms have been found to experience elevated rates of school absenteeism and dropout, cultism, social violence, and engagement in other social ills (Tunde-Ayinmode, 2010). Some scholars have argued that depression may be both a catalyst and a consequence of these academic challenges (Verboom, Sijtsema, Verhulst, Penninx, \& Ormel, 2014). Moreover, behavioral and emotional deviance, most common among young people with mental disorders, can lead to severe stigma and exclusion from family and communities, as found in a study in Sierra Leone (Gupta \& Zimmer, 2018). Mental disorders are also linked to risky sexual behaviors, thus predisposing individuals to increased risk of HIV infections, morbidity, and mortality (Nwagu, 2016). A study in Ghana among homeless youth found that alcohol consumption was associated with four indices of risky sexual behavior (ever had sex, non-condom use, multiple sexual partners, and survival sex) (Oppong et al., 2014). In addition, heavy alcohol and substance use is associated with elevated risk of impaired brain development, brain functioning, and neuropsychological performance and longterm dependence (Adu-Gyamfi \& Brenya, 2015).

\section{Mental Health Systems and Interventions}

\section{Mental Health Systems Services for Young People in WCA}

While variations exist in the availability of mental health policies, strategies, and resources across countries in WCA, mental health services are generally delivered within: (a) mental hospitals and specialist clinics, (b) psychiatric services in general hospitals, (c) mental health services through primary health care (PHC) units or integrated mental health service, and (d) community mental health services. The majority of WCA countries have limited documentation of the extent to which mental health services are available specifically for young people (either to promote positive mental health or to treat mental disorders). This is partly because many countries in the subregion (such as Liberia, Sierra Leone, and Congo) are recovering from political instabilities and protracted civil wars that degraded health systems (Jacob et al., 2007; Semrau et al., 2015). Our reviews of the WHO-AIMS survey reports available for few WCA countries (i.e., Benin [WHO-AIMS, 2007], Nigeria [WHO-AIMS, 2006], and Ghana [WHO-AIMS, 2011]), as well as Ministry of Health and WHO Atlas reports for Sierra Leone (Sierra Leone Ministry of Health, 2009) 
and the Democratic Republic of Congo (WHO, 2011) suggest that mental health care services targeted to young people are largely unavailable (see Table 11.2).

Available outpatient, inpatient, and community-based inpatient psychiatry services in the WCA subregion do not reflect prioritization of young people's mental health needs. For instance, there are often no dedicated beds for adolescents and children in inpatient units and no community outreaches designed to target young people in neighborhoods and schools where young individuals typically spend most of their time. Most of the mental hospitals and mental health care staff in WCA are located in cities. Rural areas (where approximately $70 \%$ of the population resides) often lack essential mental health services. Regionally, patient-to-psychiatrist ratios are high, and in Sierra Leone, for example, there are just 0.02 specialist psychiatrists per 1000 people (Alemu et al., 2012). Importantly, within the WCA subregion, where access to professional psychiatric care is limited for most mental health patients, traditional and spiritual healers play a significant role in providing mental health services to individuals (Patel, 2011).

\section{Mental Health Interventions Available to Young People in WCA}

Several mental health interventions targeting young people have been implemented in the WCA subregion, including those that are providerled, community-based, peer-led, and home/family/culture-based. Several local and international nongovernmental organizations (NGOs) support mental health services in the subregion by training traditional healers and non-medical personnel (e.g., in Sierra Leone), expanding access to mental health services (e.g., in Ghana) (Hushie, 2016), and providing medicines to supplement government allocations (Roberts, Mogan, \& Asare, 2014). In post-conflict Liberia and Sierra Leone, local and external NGOs also partnered with governments and other international organizations such as the WHO to "Build Back Better" mental health systems (McDaid, Knapp, \& Raja, 2008). Other mental health interventions have utilized a variety of platforms (i.e., schools, churches, health care facilities, and digital platforms) to tackle multiple mental issues including self-esteem, life skills, self-efficacy, resilience, and coping skills. Some interventions are population-wide, including legislation (i.e., laws to control alcohol demand and restrict its access). For example, a survey to estimate alcohol policy restrictiveness reported that Equatorial Guinea and Liberia have implemented a 


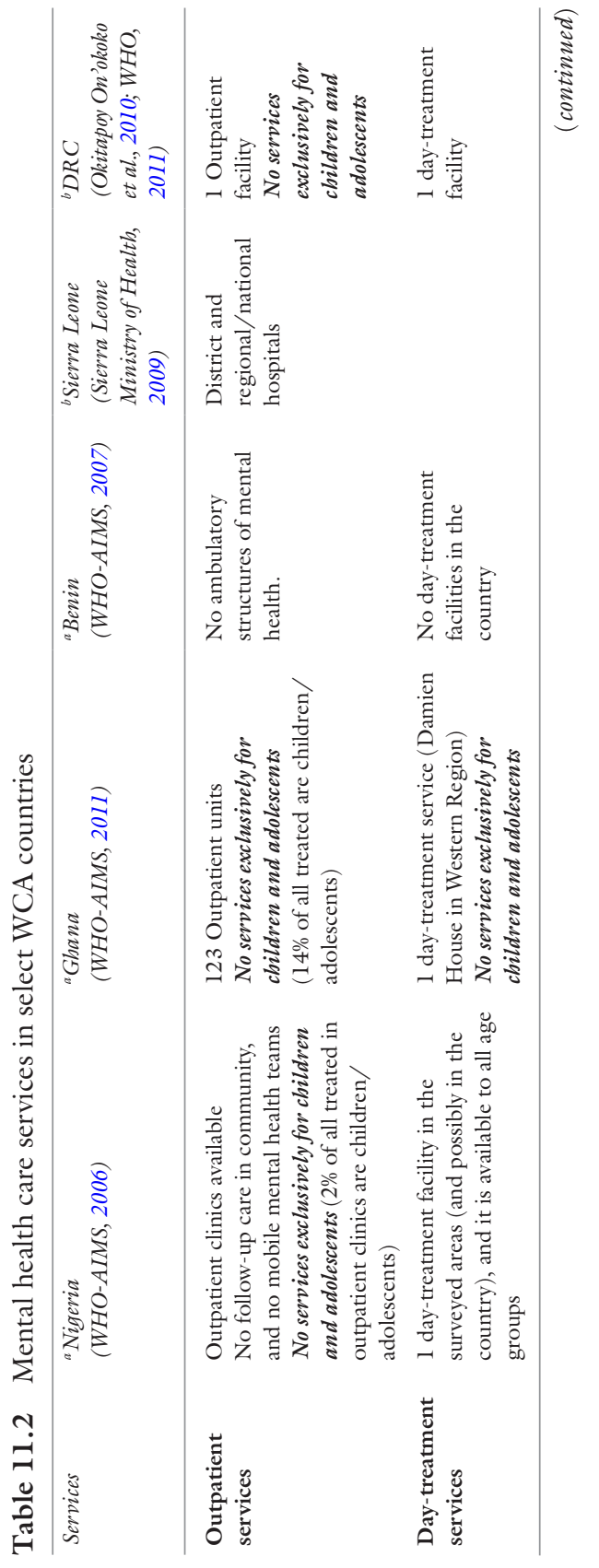




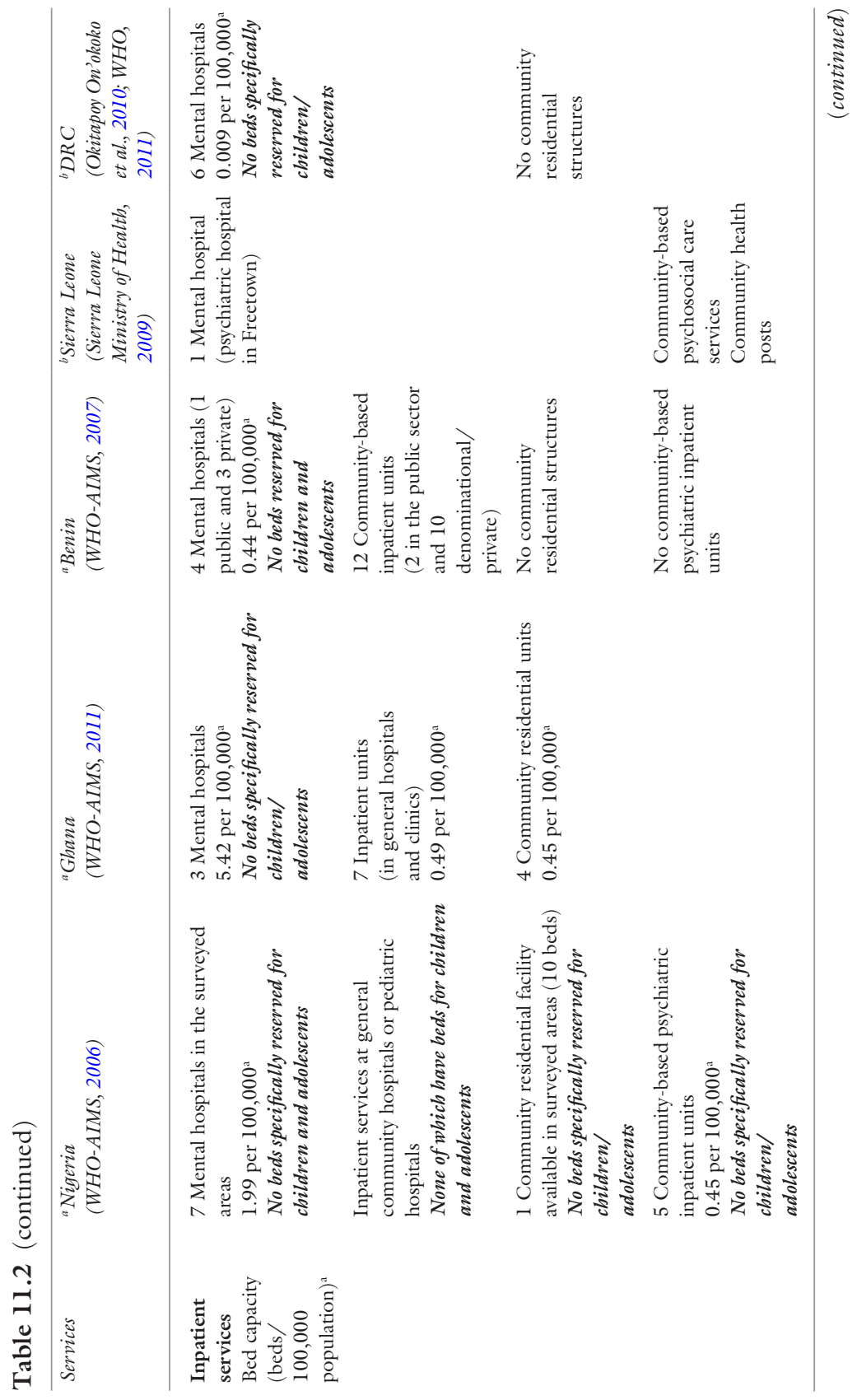




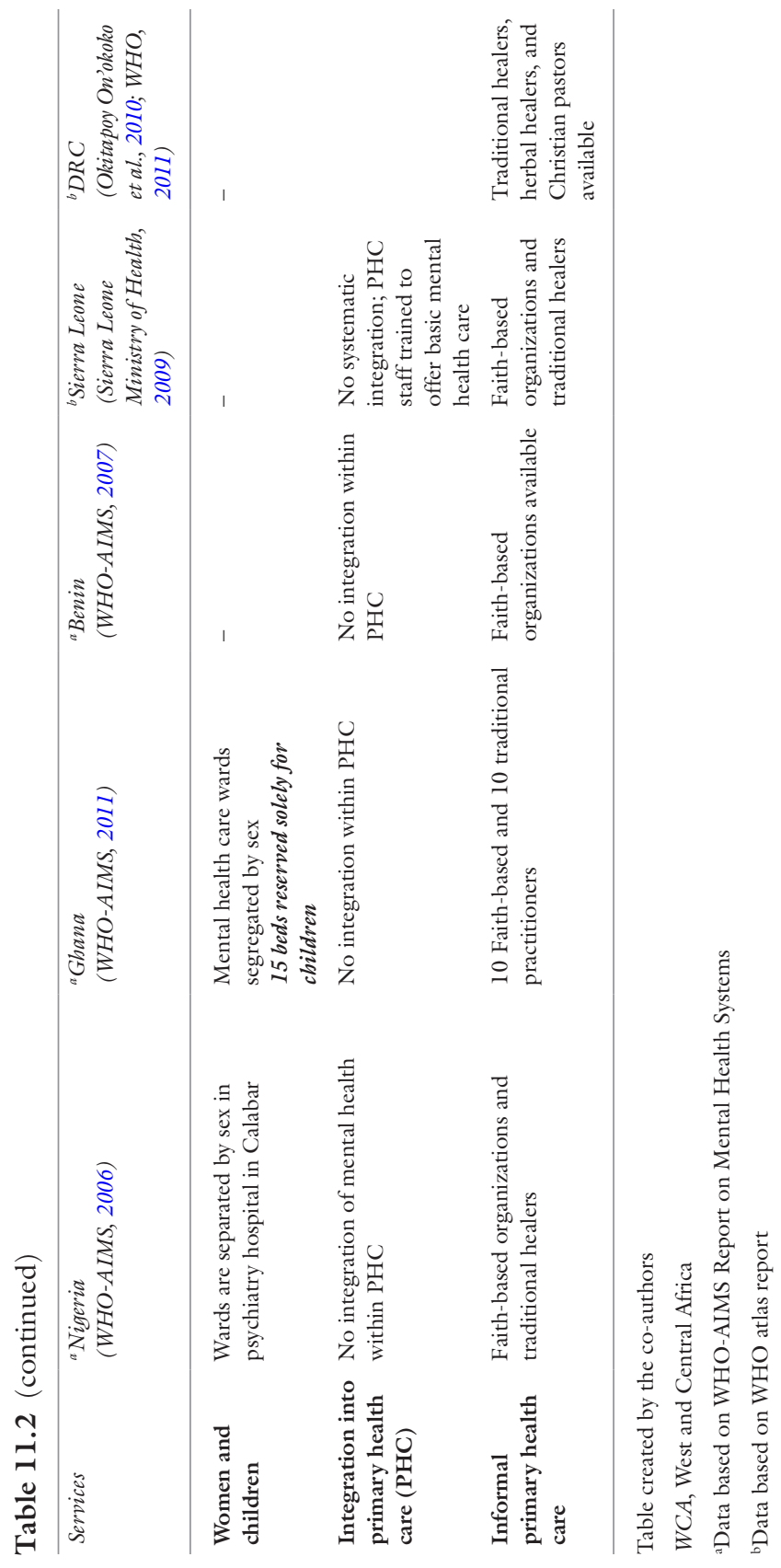


mix of alcohol control policies (Ferreira-Borges, Esser, Dias, Babor, \& Parry, 2015). Other existing population-level interventions include policies, strategies, and regulations that are meant to establish a legal framework for mental health care services, as well as limit vulnerabilities associated with mental health problems. For example, Liberia has an official mental health policy that was reviewed in 2009 (Ministry of Health and Social Welfare, 2010). Community-wide interventions implemented in collaboration with individuals within schools, families, refugee camps, and churches also exist (Das et al., 2016).

While rigorous evidence on the effectiveness of these interventions is limited, a few studies in the subregion show a wide range of beneficial effects of mental health intervention on children, families, and communities, beyond just mental health. In the Democratic Republic of Congo, for example, brief trauma-focused therapy and counseling provided by community lay counselors to children with anxiety-related complaints led to observable behavior change, symptom reduction, and improved functioning of victims (Lokuge et al., 2013). In Ghana, a national mass media and community-level stigma-reduction program using religious leaders led to increased knowledge of HIV, reduced stigma, and improved attitudes toward people living with HIV or AIDS (Boulay, Tweedie, \& Fiagbey, 2008). There is increasing interest in using schools as an opportunity to develop the foundations for positive mental health and prevent mental health problems among young people (Fazel, Patel, Thomas, \& Tol, 2014).

Notably, school-based mental health interventions have been shown to create resilience, providing young people with resources to thrive and, in adverse conditions, to cope by buffering negative stressors (Oduguwa, Adedokun, \& Omigbodun, 2017; Tolulope, Ani, Ajuwon, \& Omigbodun, 2016). In addition, school-based interventions for mental health problems have been associated with improved social functioning, academic and work performance, and general health behaviors. Key informants in one study in Nigeria acknowledged the need for school mental health programs and identified strengths, barriers, and the core components of a successful school-based program (Ibeziako, Omigbodun, \& Bella-Awusah, 2008). School-based mental health interventions can act along the entire continuum of mental health promotion and prevention and mental disorder screening/diagnosis and treatment. For example, Oduguwa et al. (2017) reported that the use of mixed-method training sessions for school children in Nigeria facilitated by the study researchers produced a positive and sustained change in knowledge and attitude toward mental illness. 
Likewise, Bella-Awusah et al. (2016) demonstrated that using a schoolbased cognitive behavioral therapy program (CBT) reduced depression symptoms among adolescents in Nigeria. The same strategy was effective among multi-symptomatic war-affected youth (aged 15 to 24 years) in Sierra Leone (Betancourt et al., 2014).

\section{Challenges of Promoting Mental Health for Young PeOple in WCA}

Several challenges related to legislation and policy, finances and resources, organization and planning, and availability of appropriately adapted evidence-based interventions and training affect mental health promotion among young people in the WCA subregion. Underlying these factors are specific issues such as lack of data on the burden of mental disorders, unavailability of mental health services, as well as lack of trained mental health professionals and scarcity of resources (Abdulmalik et al., 2014). Data on the burden of mental disorders in young people and risk and protective factors are important to inform appropriate resource allocation and to support policies that address mental health needs. Unfortunately, data are rarely available, largely due to lack of services, absence of a national focal point for mental health services targeting young people, fragmentation in services, and lack of data collection systems. Consequently, large data gaps exist due to the asymmetrical balance between the mental disorders burden and the resources available to deal with it (Prince et al., 2007).

The high costs of mental health care also hinder the provision of quality mental health services for young people in most LMICs. Mental disorders are some of the most expensive health conditions to treat, and in most SSA countries, treatment facilities are limited and often inaccessible to much of the population (Sosso \& Philippe, 2016). In settings of poverty, unemployment, and lack of medical insurance or social security, most young people experience mental disorders with very limited support. Further, whereas the WHO (through the Mental Health Gap Action Program) has recommended a range of psychosocial and pharmacological interventions for LMICs, many commonly used drugs are still not available in most WCA countries (Keynejad, Dua, Barbui, \& Thornicroft, 2017).

While studies in Nigeria and Ghana have reported that mental health literacy is abysmally low among adolescents, worse are the societal and community stereotypes and prejudices resulting from misconceptions 
about mental illness. These misunderstandings of mental disorders have led to severe stigma in these settings (Gureje et al., 2005; Kleintjes et al., 2010). Detailed descriptions from a Togolese prayer camp, set up as a makeshift psychiatric ward, demonstrate how negative connotations and false assumptions about mental illness, as well as utter lack of any formal psychiatry services, cause individuals with schizophrenia to be locked in dark rooms and bound in chains for long unending days. Thought of as a consequence of evil spirit infestation, and most often due to an individual's own actions, mental disorder victims suffer from societal stigma, which significantly limits opportunities for proper health care and delays their seeking of treatment services (Ronzoni, Dogra, Omigbodun, Bella, \& Atitola, 2010).

\section{Gaps in Research and Programming}

Despite the WHO's Mental Health Gap Action Plan that sought to increase the profile of young people's mental health, virtually all WCA countries lack clearly defined policies and programs targeting young people. For instance, Nigeria lacks a child and adolescent mental health $(\mathrm{CAMH})$ strategy, and $\mathrm{CAMH}$ issues have remained obscure to the country's policy-makers (Atilola et al., 2014). Low prioritization of young people's mental health by policy-makers is explained in part by the fact that mental illness has historically not been well understood (i.e., it is considered a taboo and is thought to be self-inflicted and incurable). Mental illness victims experience marked stigmatization. For a long time, traditional healers and religious actors were the source of care for mentally ill patients. These attitudes and practices are still deeply rooted in WCA populations (Aina, 2004), including among policy-makers. Consequently, this has led to negative impacts on service availability, coordination and delivery, resource allocation, and accountability (Kieling et al., 2011).

Data on the prevalence and burden of mental disorders in young people of WCA are based on small, nonrepresentative surveys. There is a need to improve surveillance and generate data (including estimates of prevalence rates and documentation of risk factors, protective factors, assessed needs, and tested interventions), to help guide areas of preventive interventions and programmatic focus to enhance mental health and wellbeing in the WCA countries (Jacob et al., 2007). 
Efforts to improve awareness and knowledge, while reducing stigma associated with mental disorders, are critically needed, since they affect treatment-seeking behavior, symptom detection, and disclosure for early treatment. There is increasing interest in population and community-wide strategies such as social-marketing campaigns using mass media channels, social media, and social contact events to destigmatize mental disorders and reduce substance dependence (Andreason, 2004; Sampogna et al., 2017; Scheier \& Grenard, 2010). These approaches could potentially reduce stigma and elicit positive attitudes among young people with regard to mental health problems. Also, there is a need for research to gain a deeper understanding of the variations in gender with regard to the burden and drivers of poor mental health, as well as the applicable gendered interventions. More evaluation research is needed to decipher important dimensions of public mental health interventions, such as their reach, effectiveness, adoption, implementation, and maintenance over time. While several interventions have been reported to have positive effects in the WCA subregion, very little is known about the extent to which these findings are appropriate to other settings.

\section{Implications for Research and Programming on Mental Health of Young People}

With limited existing data and in the absence of needs assessments to identify gaps and areas of action to enhance access, quality, and availability of mental health care for young people in the subregion, mental health care remains a relatively low priority. Improving the available unmet needs data would create a basis for investment in young people's mental health and monitoring and evaluation of these investments. Awareness of mental health is dismally low across the population (including among health care workers and policy-makers), further reflecting the low attention accorded to mental health. Employing wide population-based education and awareness strategies with a broader reach, such as social-marketing approaches employed via social media channels, mass media, and mobile phones, could reach large numbers of people simultaneously and could potentially reduce stigma associated with mental health and improve awareness.

Research is also needed on how to scale up existing mental health services targeting young people, especially the vulnerable individuals in remote settings, with limited access to services. Potential approaches to scale up these services include availing services for young people within 
the current mental health facilities (e.g., by increasing bed capacities reserved for children/adolescents within inpatient care units); supporting capacity building of the professional staff (e.g., nurses and doctors) and informal staff (e.g., lay workers, community health volunteers, and nonspecialists); and incorporating ideas such as task-shifting and task-sharing to address large numbers of patients (whose mental health problems are not severe). With respect to task-shifting, research is needed on the possible use of non-specialist health care providers to screen and refer young people to physicians. Further research is also needed on the development of tools for screening and diagnosis, as well as protocols for treatment, low-cost treatments and therapies, and the integration of mental health care packages within primary health care (PHC) services, to take advantage of already existing service delivery platforms and leverage their resources (such as staff, data collection systems, and referral pathways).

\section{ConClusion}

In this study, we sought to understand the burden of mental and substance use disorders, their drivers, and their impacts among young people in WCA. Our review of the literature showed that the prevalence of mental disorders among young people ranged between $12 \%$ and $30 \%$ in the WCA subregion, with conduct, anxiety, and depressive disorders being the most common disorders. In line with previous studies (Bradley, 2001), we found gendered differences in the epidemiology of poor mental health, with adolescent girls being more vulnerable to depression than boys. A significant number of young people in primary and secondary schools were reported to use substances such as marijuana and cocaine, with a majority involved in alcohol abuse. There was a significant variation in the prevalence of mental disorders among young people across the WCA subregion. These differences may be explained by the heterogeneity in the methodologies used to diagnose mental health problems and varying degrees of exposures to risk factors and protective factors.

Multiple factors drive poor mental health and substance use disorders in young people in WCA. More worrying is the co-occurrence of risk factors for mental health problems, including social factors (such as poor family relations) and structural factors (e.g., poverty, high unemployment, urbanization, rapid social and economic change, conflict, and natural disasters) in these settings (Allen et al., 2014). The co-occurrence of these risk factors increases exposure to the stressors that precipitate the onset 
and continuity of mental health problems. Untreated mental disorders may result in severe negative consequences, the most serious of which is suicide. For instance, depression has been found to be the strongest single risk factor for attempted or completed suicides (Beautrais, Joyce, \& Mulder, 1996). Apart from worsening the livelihoods of young people, poor mental health may predispose young people to infectious diseases (such as HIV) or worsen outcomes for diseases (such as TB) because of increased propensity to engage in risky sexual behavior and poor adherence to treatment among those with mental health and substance disorders (Nwagu, 2016; Oppong et al., 2014).

Despite the burden and impact of mental disorders among young people in WCA, programming for these key populations remains insufficient, and lack of policy, limited resources, stigma, discrimination, and socioeconomic barriers may prevent many people from accessing mental health care. Several psychosocial and pharmacological interventions (along the continuum of primary, secondary, and tertiary prevention) for mental and substance use disorders have been described in many LMICs, including WCA (Barry et al., 2013). However, data on the effectiveness of these interventions is weak or lacking, yet such evidence is critical to inform scale-up of interventions. Systematic reviews of school-based interventions from HICs (and few from WCA) show they have great potential to facilitate early detection and management of mental disorders in young people, with positive effects not only on mental health, but also on academic and work performance and general health behaviors (Fazel et al., 2014). Increasing school enrollment rates could place schools as an optimum entry point for most early mental health interventions for young people (UNICEF, 2014). Early identification and treatment of mental and substance disorders are essential. Studies in the United States and Brazil have shown that early initiation of treatment leads to decreased morbidity and mortality, including the reduction in suicidal thoughts and behaviors (March et al., 2009). Schooling also improves self-esteem, problem-solving and social skills, positive thinking, good physical health, educational opportunities, positive parenting, and availability of social support systems, which can positively modify individual response to psychosocial stress (Opler, Sodhi, Zaveri, \& Madhusoodanan, 2010).

Further research is required to improve evidence on the burden and impact of mental health problems among young people in the WCA subregion. In particular, research is needed to identify young people who may be especially vulnerable to poor mental health including those in 
conflict and post-conflict settings, those living with chronic illness, sexual minorities, and homeless youth. Studies investigating the utilization of mental health services by young people and effective and scalable mental health interventions are also needed. With respect to the latter, our findings underscore the need for programmatic investment toward training of primary health care workers on mental health care and community-based mental health care services for young people.

In conclusion, the lack of data on the burden, drivers, and impact of mental disorders, as well as the utilization of mental services by young people in the WCA subregion, acutely hampers any action to improve mental health care for young people. A fair amount of evidence exists on mental health interventions amenable for scale-up for young people in the subregion; however, further research is required to elucidate other dimensions of these interventions such as cost effectiveness. There is a need for programmatic focus by WCA governments, donors, and other stakeholders on training of mental health care providers and the provision of quality of mental health services to young people. An integrated approach to the delivery of mental health services that includes a focus on schools, communities, households, and other settings where youth participate actively would be key to reaching the most vulnerable young people with much needed care and services.

\section{REFERENCES}

Abdulmalik, J., Fadahunsi, W., Kola, L., Nwefoh, E., Minas, H., Eaton, J., et al. (2014). The Mental Health Leadership and Advocacy Program (mhLAP): A pioneering response to the neglect of mental health in Anglophone West Africa. International Journal of Mental Health Systems, 8(1), 5. https://doi. org/10.1186/1752-4458-8-5

Abiodun, O. A. (1992). Emotional illness in a paediatric population in Nigeria. East African Medical Journal, 69(10), 557-559.

Addo, B., Mainoo, G. O., Dapaah, J. M., \& Babayara, M. N. K. (2016). Prevalence of substance use in a sample of Ghanaian adolescents experiencing parental divorce. Journal of Child \& Adolescent Substance Abuse, 25(5), 428-437. https://doi.org/10.1080/1067828X.2015.1056867

Adewuya, A. O. (2005). Validation of the alcohol use disorders identification test (audit) as a screening tool for alcohol-related problems among Nigerian university students. Alcohol and Alcoholism, 40(6), 575-577.

Adewuya, A. O., Afolabi, M. O., Ola, B. A., Ogundele, O. A., Ajibare, A. O., \& Oladipo, B. F. (2007). Psychiatric disorders among the HIV-positive popula- 
tion in Nigeria: A control study. Journal of Psychosomatic Research, 63(2), 203-206.

Adu-Gyamfi, S., \& Brenya, E. (2015). The marijuana factor in a university in Ghana: A survey. Humanities \& Social Sciences, 8(11), 2162-2182. https:// doi.org/10.17516/1997-1370-2015-8-11-2162-2182

Aina, O. F. (2004). Mental illness and cultural issues in West African films: Implications for orthodox psychiatric practice. Medical Humanities, 30(1), 23-26. https://doi.org/10.1136/jmh.2003.000152

Akpan, M. U., Ojinnaka, N. C., \& Ekanem, E. (2010). Behavioural problems among schoolchildren in Nigeria. South African Journal of Psychiatry, $16(2), 50-55$.

Alemu, W., Funk, M., Gakurah, T., Bash-Taqi, D., Bruni, A., Sinclair, J., et al. (2012). WHO profile on mental health in development (WHO proMIND): Sierra Leone. Retrieved March 8, 2018, from http://www.who.int/mental_health/ policy/country/sierra_leone_country_summary_2012.pdf

Allen, J., Balfour, R., Bell, R., \& Marmot, M. (2014). Social determinants of mental health. International Review of Psychiatry, 26(4), 392-407. https://doi.org $/ 10.3109 / 09540261.2014 .928270$

American Psychiatric Association (APA). (2000). Diagnostic and statistical manual of mental disorders (4th ed.). Washington, DC: American Psychiatric Association.

Andreason, A. R. (2004). A social marketing approach to changing mental health practices directed at youth and adolescents. Health Marketing Quarterly, 21(4), 51-75. https://doi.org/10.1300/J026v2ln04_04

Asare, M., \& Danquah, S. (2016). Observation report from clinical practice in Ghana: Children and adolescent depression. Journal of Child and Adolescent Behavior, 4(2), 286. https://doi.org/10.4172/2375-4494.1000286

Atilola, O., Ayinde, O., Emedoh, C. T., \& Oladimeji, O. (2014). State of the Nigerian child - Neglect of child and adolescent mental health: A review. Paediatrics and International Child Health, 35(2), 135-143. https://doi.org $/ 10.1179 / 2046905514 Y .0000000137$

Barry, M. M., Clarke, A. M., Jenkins, R., \& Patel, V. (2013). A systematic review of the effectiveness of mental health promotion interventions for young people in low and middle income countries. BMC Public Health, 13, 835. https://doi. org/10.1186/1471-2458-13-835

Beautrais, A. L., Joyce, P. R., \& Mulder, R. T. (1996). Risk factors for serious suicide attempts among youths aged 13 through 24 years. Journal of the American Academy of Child and Adolescent Psychiatry, 35(9), 1174-1182. https://doi.org/10.1097/00004583-199609000-00015

Belfer, M. L. (2008). Child and adolescent mental disorders: The magnitude of the problem across the globe. Journal of Child Psychology and Psychiatry and Allied Disciplines, 49(3), 226-236. https://doi.org/10.1111/j.1469-7610. 2007.01855.x 
Bella-Awusah, T., Ani, C., Ajuwon, A., \& Omigbodun, O. (2016). Effectiveness of brief school-based, group cognitive behavioural therapy for depressed adolescents in south west Nigeria. Child and Adolescent Mental Health, 21(1), 44-50. https://doi.org/10.1111/camh.12104

Betancourt, T., Borisova, I. I., Williams, T. P., Brennan, R. T., Whitfield, T. H., de la Soudiere, M., et al. (2010). Sierra Leone's former child soldiers: A follow-up study of psychosocial adjustment and community reintegration. Child Development, 81(4), 1077-1095. https://doi.org/10.1111/j.1467-8624. 2010.01455.x

Betancourt, T., McBain, R., Newnham, E., \& Brennan, R. (2013). Context matters: Community characteristics and mental health among war-affected youth in Sierra Leone. Journal of Child Psychology and Psychiatry and Allied Disciplines, 55(3), 217-226. https://doi.org/10.1111/jcpp.12131

Betancourt, T., McBain, R., Newnham, E. A., Akinsulure-Smith, A. M., Brennan, R. T., Weisz, J. R., et al. (2014). A behavioral intervention for war-affected youth in Sierra Leone: A randomized controlled trial. Journal of the American Academy of Child and Adolescent Psychiatry, 53(12), 1288-1297. https://doi. org/10.1016/j.jaac.2014.09.011

Betancourt, T., Newnham, E. A., McBain, R., \& Brennan, R. T. (2018). Posttraumatic stress symptoms among former child soldiers in Sierra Leone: Follow-up study. British Journal of Psychiatry, 203(3), 196-202. https://doi. org/10.1192/bjp.bp.112.113514

Bloom, D. E., Cafiero, E. T., Jané-Llopis, E., Abrahams-Gessel, S., Bloom, L. R., Fathima, S., et al. (2011). The global economic burden of non-communicable diseases. Retrieved March 11, 2018, from http://www.weforum.org/docs/ WEF_Harvard_HE_GlobalEconomicBurdenNonCommunicableDiseases_ 2011.pdf

Boulay, M., Tweedie, I., \& Fiagbey, E. (2008). The effectiveness of a national communication campaign using religious leaders to reduce HIV-related stigma in Ghana. African Journal of AIDS Research, 7(1), 133-141. https://doi. org/10.2989/AJAR.2008.7.1.13.441

Bradley, S. J. (2001). Anxiety and mood disorders in children and adolescents: A practice update. Paediatrics \& Child Health, 6(7), 459-463.

Burns, A., Daileader, C., \& Finger, W. (2004). Reaching out-of-school youth with reproductive bealth and HIV/AIDS information and services (YouthNet Issues Paper 4). Arlington, VA: Family Health International, YouthNet Program.

Burns, J. K. (2012). The social determinants of schizophrenia: An African journey in social epidemiology. Public Health Reviews, 34(2), 1-18. https://doi. org/10.1007/bf03391676

Charlson, F., Baxter, A. J., Dua, T., Degenhardt, L., Whiteford, H. A., \& Vos, T. (2014). Excess mortality from mental, neurological, and substance use disorders 
in the global burden of disease study 2010. Epidemiology and Psychiatric Sciences, 24(2), 121-140. https://doi.org/10.1017/S2045796014000687

Charlson, F., Diminic, S., Lund, C., Degenhardt, L., \& Whiteford, H. A. (2014). Mental and substance use disorders in sub-Saharan Africa: Predictions of epidemiological changes and mental health workforce requirements for the next 40 years. PLoS One, 9(10), el10208. https://doi.org/10.1371/journal. pone. 0110208

Chesney, E., Goodwin, G. M., \& Fazel, S. (2014). Risks of all-cause and suicide mortality in mental disorders: A meta-review. World Psychiatry, 13(2), 153160. https://doi.org/10.1002/wps.20128

Coalition to Stop the Use of Child Soldiers. (2008). Child soldiers: Global report 2008. London: Author.

Cortina, M. A., Sodha, A., Fazel, M., \& Ramchandani, P. G. (2012). Prevalence of child mental health problems in sub-Saharan Africa: A systematic review. Archives of Pediatrics and Adolescent Medicine, 166(3), 276-281. https://doi. org/10.1001/archpediatrics.2011.592

Daar, A. S., Jacobs, M., Wall, S., Groenewald, J., Eaton, J., Patel, V., et al. (2014). Declaration on mental health in Africa: moving to implementation. Global Health Action, 7(1), 24589. https://doi.org/10.3402/gha.v7.24589

Das, J. K., Salam, R. A., Lassi, Z. S., Khan, M. N., Mahmood, W., Patel, V., et al. (2016). Interventions for adolescent mental health: An overview of systematic reviews. Journal of Adolescent Health, 59(4, Suppl), S49-S60. https://doi. org/10.1016/j.jadohealth.2016.06.020

Doku, P. (2016). Depression, delinquency and peer problems among children and adolescents affected by HIV/AIDS in Ghana: The mediating role of child labour. Journal of Depression \& Anxiety, 05(2), 221. https://doi. org/10.4172/2167-1044.1000221

Doran, N., Luczak, S. E., Bekman, N., Koutsenok, I., \& Brown, S. A. (2012). Adolescent substance use and aggression: A review. Criminal Justice and Behavior, 39(6), 748-769. https://doi.org/10.1177/0093854812437022

Embleton, L., Mwangi, A., Vreeman, R., Ayuku, D., \& Braitstein, P. (2013). The epidemiology of substance use among street children in resource-constrained settings: A systematic review and meta-analysis. Addiction, 108(10), 17221733. https://doi.org/10.1111/add.12252

Erskine, H. E., Baxter, A. J., Patton, G., Moffitt, T. E., Patel, V., Whiteford, H. A., et al. (2017). The global coverage of prevalence data for mental disorders in children and adolescents. Epidemiology and Psychiatric Sciences, 26(4), 395402. https://doi.org/10.1017/s2045796015001158

Esan, O. B., Kola, L., \& Gureje, O. (2012). Mental disorders and earnings: Results from the Nigerian National Survey of Mental Health and Well-Being (NSMHW). The Journal of Mental Health Policy and Economics, 15(2), 77-82. 
Fazel, M., Patel, V., Thomas, S., \& Tol, W. (2014). Mental health interventions in schools in low-income and middle-income countries. The Lancet Psychiatry, 1(5), 388-398. https://doi.org/10.1016/S2215-0366(14)70357-8

Ferrari, A. J., Charlson, F. J., Norman, R. E., Patten, S. B., Freedman, G., Murray, C. J. L., et al. (2013). Burden of depressive disorders by country, sex, age, and year: Findings from the global burden of disease study 2010. PLoS Medicine, 10(11), el001547. https://doi.org/10.1371/journal.pmed.1001547

Ferreira-Borges, C., Esser, M. B., Dias, S., Babor, T., \& Parry, C. D. H. (2015). Alcohol control policies in 46 African countries: Opportunities for improvement. Alcohol and Alcoholism, 50(4), 470-476. https://doi.org/10.1093/ alcalc/agv036

Gupta, L., \& Zimmer, C. (2018). Psychosocial intervention for war-affected children in Sierra Leone. British Journal of Psychiatry, 192(3), 212-216. https:// doi.org/10.1192/bjp.bp.107.038182

Gureje, O., Chisholm, D., Kola, L., Lasebikan, V., \& Saxena, S. (2007). Costeffectiveness of an essential mental health intervention package in Nigeria. World Psychiatry, 6(1), 42-48.

Gureje, O., Lasebikan, V. O., Ephraim-Oluwanuga, O., Olley, B. O., \& Kola, L. (2005). Community study of knowledge of and attitude to mental illness in Nigeria. BritishJournal of Psychiatry, 186, 436-441. https://doi.org/10.1192/ bjp.186.5.436

Gureje, O., Lasebikan, V. O., Kola, L., \& Makanjuola, V. A. (2018). Lifetime and 12-month prevalence of mental disorders in the Nigerian survey of mental health and well-being. British Journal of Psychiatry, 188(5), 465-471. https:// doi.org/10.1192/bjp.188.5.465

Hushie, M. (2016). Public-non-governmental organisation partnerships for health: An exploratory study with case studies from recent Ghanaian experience. BMC Public Health, 16(1), 963. https://doi.org/10.1186/ s12889-016-3636-2

Ibeziako, P., Omigbodun, O., \& Bella-Awusah, T. (2008). Assessment of need for a school-based mental health programme in Nigeria: Perspectives of school administrators. International Review of Psychiatry, 20(3), 271-280. https:// doi.org/10.1080/09540260802000354

Igwe, W., Ngozi, O., Ejiofor, S. O., Emechebe, G. O., \& Ibe, B. C. (2009). Sociodemographic correlates of psychoactive substance abuse among secondary school students in Enugu, Nigeria. European Journal of Social Sciences, 12(2), 277-283.

Institute for Health Metrics and Evaluation. (2017). GBD compare | Viz hub. Retrieved March 12, 2018, from https:/ /vizhub.healthdata.org/gbd-compare/ Ismayilova, L., Gaveras, E., Blum, A., Tô-Camier, A., \& Nanema, R. (2016). Maltreatment and mental health outcomes among ultra-poor children in Burkina Faso: A latent class analysis. PLoS One, 11(10), e0164790. 
Izugbara, C., Wekesah, F., Kabiru, C., Amo-Adjei, J., Tsala Dimbuene, Z., \& Emina, J. (2017). Young people in West and Central Africa: Health, demographic, education and socioeconomic indicators. Nairobi: African Population and Health Research Center.

Jack-Ide, I. O., \& Uys, L. (2013). Barriers to mental health services utilization in the Niger Delta region of Nigeria: Service users' perspectives. The Pan African Medical Journal, 14, 159. https://doi.org/10.11604/pamj.2013.14.159.1970

Jacob, K. S., Sharan, P., Mirza, I., Garrido-Cumbrera, M., Seedat, S., Mari, J. J., et al. (2007). Mental health systems in countries: Where are we now? Lancet, 370(9592), 1061-1077. https://doi.org/10.1016/s0140-6736(07)61241-0

Joint United Nations Programme on HIV/AIDS (UNAIDS), \& United Nations International Children's Emergency Fund (UNICEF). (2016). Step up the pace: Towards an AIDS-free generation in West and Central Africa. Dakar: UNICEF.

Kabiru, C. W., Beguy, D., Crichton, J., \& Ezeh, A. C. (2010). Self-reported drunkenness among adolescents in four sub-Saharan African countries: Associations with adverse childhood experiences. Child and Adolescent Psychiatry and Mental Health, 4(1), 17. https://doi.org/10.1186/ 1753-2000-4-17

Kashala, E., Elgen, I., Sommerfelt, K., \& Tylleskar, T. (2005). Teacher ratings of mental health among school children in Kinshasa, Democratic Republic of Congo. European Child and Adolescent Psychiatry, 14(4), 208-215. https:// doi.org/10.1007/s00787-005-0446-y

Kayembe, P. K., Mapatano, M. A., Fatuma, A. B., Nyandwe, J. K., Mayala, G. M., Kokolomami, J. I., et al. (2008). Knowledge of HIV, sexual behavior and correlates of risky sex among street children in Kinshasa, Democratic Republic of Congo. East African Journal of Public Health, 5(3), 186-192.

Keynejad, R. C., Dua, T., Barbui, C., \& Thornicroft, G. (2017). WHO Mental Health Gap Action Programme (mhGAP) intervention guide: A systematic review of evidence from low and middle-income countries. Evidence Based Mental Health, 21(1), 30-34.

Kieling, C., Baker-Henningham, H., Belfer, M., Conti, G., Ertem, I., Omigbodun, O., et al. (2011). Child and adolescent mental health worldwide: Evidence for action. Lancet, 378(9801), 1515-1525. https://doi.org/10.1016/ s0140-6736(11)60827-1

Kleintjes, S., Lund, C., \& Flisher, A. J. (2010). A situational analysis of child and adolescent mental health services in Ghana, Uganda, South Africa and Zambia. African Journal of Psychiatry, 13(2), 132-139.

Klitzing, K., Döhnert, M., Kroll, M., \& Grube, M. (2015). Mental disorders in early childhood. Dentsches Ärzteblatt International, 112(21-22), 375-386. https://doi.org/10.3238/arztebl.2015.0375 
Kohn, R., Saxena, S., Levav, I., \& Saraceno, B. (2004). The treatment gap in mental health care. Bulletin of the World Health Organization, 82(11), 858-866. https://doi.org/10.1590/S0042-96862004001100011

Kretzschmar, I., Nyan, O., Mendy, A., \& Janneh, B. (2012). Mental health in the Republic of The Gambia. International Psychiatry, 9(2), 38-40.

Lokuge, K., Shah, T., Pintaldi, G., Thurber, K., Martínez-Viciana, C., Cristobal, M., et al. (2013). Mental health services for children exposed to armed conflict: Médecins Sans Frontières' experience in the Democratic Republic of Congo, Iraq and the occupied Palestinian territory. Paediatrics and International Child Health, 33(4), 259-272. https://doi.org/10.1179/2046905513Y.0000000098

Lund, C., Breen, A., Flisher, A. J., Kakuma, R., Corrigall, J., Joska, J. A., et al. (2010). Poverty and common mental disorders in low and middle income countries: A systematic review. Social Science \& Medicine, 71(3), 517-528. https://doi.org/10.1016/j.socscimed.2010.04.027

Lund, C., De Silva, M., Plagerson, S., Cooper, S., Chisholm, D., Das, J., et al. (2011). Poverty and mental disorders: Breaking the cycle in low-income and middle-income countries. The Lancet, 378(9801), 1502-1514. https://doi. org/10.1016/S0140-6736(11)60754-X

March, J., Silva, S., Curry, J., Wells, K., Fairbank, J., Burns, B., et al. (2009). The Treatment for adolescents with depression study (TADS): Outcomes over 1 year of naturalistic follow-up. American Journal of Psychiatry, 166(10), 11411149. https://doi.org/10.1176/appi.ajp.2009.08111620

Mars, B., Burrows, S., Hjelmeland, H., \& Gunnell, D. (2014). Suicidal behaviour across the African continent: A review of the literature. BMC Public Health, 14(1), 606. https://doi.org/10.1186/1471-2458-14-606

McDaid, D., Knapp, M., \& Raja, S. (2008). Barriers in the mind: Promoting an economic case for mental health in low- and middle-income countries. World Psychiatry, 7(2), 79-86.

McKinnon, B., Gariepy, G., Sentenac, M., \& Elgar, F. J. (2016). Adolescent suicidal behaviours in 32 low- and middle-income countries. Bulletin of the World Health Organization, 94(5), 340-350f. https://doi.org/10.2471/ blt.15.163295

Ministry of Health and Social Welfare. (2010). Liberia national mental health policy. Retrieved March 15, 2018, from http://apps.who.int/medicinedocs/ documents/s18362en/s18362en.pdf

Mokdad, A. H., Forouzanfar, M. H., Daoud, F., Mokdad, A. A., El Bcheraoui, C., Moradi-Lakeh, M., et al. (2016). Global burden of diseases, injuries, and risk factors for young people's health during 1990-2013: A systematic analysis for the global burden of disease study 2013. The Lancet, 387(10036), 2383-2401. https://doi.org/10.1016/S0140-6736(16)00648-6

Ngasa, S. N., Sama, C. B., Dzekem, B. S., Nforchu, K. N., Tindong, M., Aroke, D., et al. (2017). Prevalence and factors associated with depression among 
medical students in Cameroon: A cross-sectional study. BMC Psychiatry, 17(1), 216. https://doi.org/10.1186/s12888-017-1382-3

Ngom, M. (2017). UNFPA Regional Office for West and Central Africa - Annual Report 2016: Working together to put young people and women first. Retrieved March 17, 2018, from https://reliefweb.int/report/world/unfpa-regionaloffice-west-and-central-africa-annual-report-2016-working-together-put

Nwagu, E. N. (2016). Alcohol and drug usage; and adolescents' sexual behaviour in Nigeria. Health Promotion International, 31(2), 405-413. https://doi. org/10.1093/heapro/dav001

Oduguwa, A. O., Adedokun, B., \& Omigbodun, O. O. (2017). Effect of a mental health training programme on Nigerian school pupils' perceptions of mental illness. Child and Adolescent Psychiatry and Mental Health, 11(1), 19. https:// doi.org/10.1186/s13034-017-0157-4

Okitapoy On'okoko, M., Jenkins, R., Mampunza Ma Miezi, S., Okitundu, D., Andjafono, L. E., \& Muteba Mushidi, I. (2010). Mental health in the Democratic Republic of Congo: A post-crisis country challenge. International Psychiatry, 7(2), 41-42. https://doi.org/10.1192/S1749367600005737

Omigbodun, O. (2004). Psychosocial issues in a child and adolescent psychiatric clinic population in Nigeria. Social Psychiatry and Psychiatric Epidemiology, 39(8), 667-672. https://doi.org/10.1007/s00127-004-0793-x

Opler, M., Sodhi, D., Zaveri, D., \& Madhusoodanan, S. (2010). Primary psychiatric prevention in children and adolescents. Annals of Clinical Psychiatry, 22(4), 220-234.

Oppong, K., Meyer-Weitz, A., \& Petersen, I. (2014). Substance use and risky sexual behaviours among street connected children and youth in Accra, Ghana. Substance Abuse Treatment, Prevention, and Policy, 9, 45. https://doi.org/10. 1186/1747-597X-9-45

Oshodi, Y. O., Abdulmalik, J., Ola, B., James, B. O., Bonetto, C., Cristofalo, D., et al. (2014). Pattern of experienced and anticipated discrimination among people with depression in Nigeria: A cross-sectional study. Social Psychiatry and Psychiatric Epidemiology, 49(2), 259-266. https://doi.org/10.1007/ s00127-013-0737-4

Pacione, L., Measham, T., \& Rousseau, C. (2013). Refugee children: Mental health and effective interventions. Current Psychiatry Reports, 15(2), 341. https://doi.org/10.1007/s11920-012-0341-4

Patel, V. (2011). Traditional healers for mental health care in Africa. Global Health Action, 4, 7956. https://doi.org/10.3402/gha.v4i0.7956

Peltzer, K., \& Pengpid, S. (2018). Cannabis and amphetamine use and associated factors among school-going adolescents in nine African countries. Journal of Child \& Adolescent Substance Abuse, 27(2), 112-118. https://doi.org/10.108 0/1067828X.2017.1420512 
Prince, M., Patel, V., Saxena, S., Maj, M., Maselko, J., Phillips, M. R., et al. (2007). No health without mental health. Lancet, 370(9590), 859-877. https://doi. org/10.1016/s0140-6736(07)61238-0

Read, U. M., Adiibokah, E., \& Nyame, S. (2009). Local suffering and the global discourse of mental health and human rights: An ethnographic study of responses to mental illness in rural Ghana. Globalization and Health, 5, 13. https://doi.org/10.1186/1744-8603-5-13

Remschmidt, H., \& Belfer, M. (2005). Mental health care for children and adolescents worldwide: A review. World Psychiatry, 4(3), 147-153.

Roberts, M., Mogan, C., \& Asare, J. B. (2014). An overview of Ghana's mental health system: Results from an assessment using the World Health Organization's Assessment Instrument for Mental Health Systems (WHO-AIMS). International Journal of Mental Health Systems, 8, 16. https://doi. org/10.1186/1752-4458-8-16

Ronzoni, P., Dogra, N., Omigbodun, O., Bella, T., \& Atitola, O. (2010). Stigmatization of mental illness among Nigerian schoolchildren. International Journal of Social Psychiatry, 56(5), 507-514. https://doi.org/10.1177/ 0020764009341230

Sampogna, G., Bakolis, I., Evans-Lacko, S., Robinson, E., Thornicroft, G., \& Henderson, C. (2017). The impact of social marketing campaigns on reducing mental health stigma: Results from the 2009-2014 Time to Change programme. European Psychiatry, 40, 116-122. https://doi.org/10.1016/j. eurpsy.2016.08.008

Saraceno, B., van Ommeren, M., Batniji, R., Cohen, A., Gureje, O., Mahoney, J., et al. (2007). Barriers to improvement of mental health services in low-income and middle-income countries. Lancet, 370(9593), 1164-1174. https://doi. org/10.1016/s0140-6736(07)61263-x

Sartorius, N. (2007). Stigma and mental health. The Lancet, 370(9590), 810-811. https://doi.org/10.1016/S0140-6736(07)61245-8

Scheier, L. M., \& Grenard, J. L. (2010). Influence of a nationwide social marketing campaign on adolescent drug use. Journal of Health Communication, 15(3), 240-271. https://doi.org/10.1080/10810731003686580

Semrau, M., Evans-Lacko, S., Alem, A., Ayuso-Mateos, J. L., Chisholm, D., Gureje, O., et al. (2015). Strengthening mental health systems in low- and middle-income countries: The emerald programme. BMC Medicine, 13(1), 79. https://doi.org/10.1186/s12916-015-0309-4

Sharma, M., Fine, S. L., Brennan, R. T., \& Betancourt, T. S. (2017). Coping and mental health outcomes among Sierra Leonean war-affected youth: Results from a longitudinal study. Development and Psychopathology, 29(1), 11-23. https://doi.org/10.1017/s0954579416001073

Sierra Leone Ministry of Health. (2009). Ministry of bealth and sanitation (MOHS). Retrieved March 21, 2018, from http://health.gov.sl/ 
Sosso, F., \& Philippe, K. (2016). The African burden of mental health. Journal of Mental Disorders and Treatment, 2(2), 122-126. https://doi.org/10.4172/ 2471-271X.1000122

Suleiman, T. G., Ohaeri, J. U., Lawal, R. A., Haruna, A. Y., \& Orija, O. B. (1997). Financial cost of treating out-patients with schizophrenia in Nigeria. British Journal of Psychiatry, 171(4), 364-368.

Tarter, R. E. (2002). Etiology of adolescent substance abuse: A developmental perspective. American Journal on Addictions, 11(3), 171-191. https://doi. org/10.1080/10550490290087965

Thela, L., Tomita, A., Maharaj, V., Mhlongo, M., \& Burns, J. K. (2017). Counting the cost of Afrophobia: Post-migration adaptation and mental health challenges of African refugees in South Africa. Transcultural Psychiatry, 54(5-6), 715-732. https://doi.org/10.1177/1363461517745472

Tims, F. M., Dennis, M. L., Hamilton, N., Buchan, J. B., Diamond, G., Funk, R., et al. (2002). Characteristics and problems of 600 adolescent cannabis abusers in outpatient treatment. Addiction, 97(S1), 46-57.

Tunde-Ayinmode, M. (2010). Audit of child and adolescent psychiatry in a teaching hospital in Nigeria: Prevalence, pattern and implication for improved services. South African Journal of Psychiatry, 16(1), 20-26. https://doi. org/10.4102/sajpsychiatry.vl6il.209

Tunde-Ayinmode, M., Adegunloye, O., Ayinmode, B., \& Abiodun, O. (2012). Psychiatric disorders in children attending a Nigerian primary care unit: Functional impairment and risk factors. Child and Adolescent Psychiatry and Mental Health, 6(1), 28. https://doi.org/10.1186/1753-2000-6-28

United Nations International Children's Emergency Fund (UNICEF). (2014). Achieving universal primary education and eliminating gender disparity in education; West and Central Africa. Retrieved May 11, 2018, from https://www. unicef.org/wcaro/overview_1898.html

United Nations International Children's Emergency Fund (UNICEF). (2017a). A deadly journey for children: The central Mediterranean migration route. Retrieved April 2, 2018, from https://www.unicef.org/publications/files/ EN_UNICEF_Central_Mediterranean_Migration.pdf

United Nations International Children's Emergency Fund (UNICEF). (2017b). Over 7 million children are on the move in West and Central Africa each year [Press release]. Retrieved April 19, 2018, from https://www.unicef.org/ media/media_96585.html

United Nations International Children's Emergency Fund (UNICEF), \& Overseas Development Institute (ODI). (2009). Strengthening social protection for children: West and Central Africa. Retrieved April 23, 2018, from https://www.odi.org/ publications /3478-strengthening-social-protection-children-west-and-central-africa 
Verboom, C. E., Sijtsema, J. J., Verhulst, F. C., Penninx, B. W., \& Ormel, J. (2014). Longitudinal associations between depressive problems, academic performance, and social functioning in adolescent boys and girls. Developmental Psychology, 50(1), 247-257. https://doi.org/10.1037/a0032547

Wang, P. S., Aguilar-Gaxiola, S., Alonso, J., Angermeyer, M. C., Borges, G., Bromet, E. J., et al. (2007). Use of mental health services for anxiety, mood, and substance disorders in 17 countries in the WHO world mental health surveys. Lancet, 370(9590), 841-850. https://doi.org/10.1016/ s0140-6736(07)61414-7

Warner, L. A., \& White, H. R. (2003). Longitudinal effects of age at onset and first drinking situations on problem drinking. Substance Use and Misuse, 38(14), 1983-2016.

World Health Organization (WHO). (1992). The ICD-10 classification of mental and behavioural disorders: Clinical descriptions and diagnostic guidelines. Retrieved March 2, 2018, from http://www.who.int/iris/handle/10665/ 37958

World Health Organization (WHO). (2011). Mental health atlas Democratic Republic of Congo. Retrieved March 15, 2018, from https://www.who.int/ mental_health/evidence/atlas/profiles/cod_mh_profile.pdf?ua=1

World Health Organization Assessment Instrument for Mental Health Systems (WHO-AIMS). (2006). WHO-AIMS Report on mental health system in Nigeria. Retrieved March 16, 2018, from https://www.who.int/mental_health/evidence/nigeria_who_aims_report.pdf?ua=1

World Health Organization Assessment Instrument for Mental Health Systems (WHO-AIMS). (2007). WHO-AIMS report on mental bealth system in the Republic of Benin. Retrieved March 16, 2018, from https://www.who.int/ mental_health/WHO-AIMS_benin_English.pdf

World Health Organization Assessment Instrument for Mental Health Systems (WHO-AIMS). (2011). WHO-AIMS Report on mental health system in Ghana. Retrieved March 18,2018, from https://www.who.int/mental_health/who_ aims_country_reports/ghana_who_aims_report.pdf

Yoder, H. N. C., Tol, W. A., Reis, R., \& de Jong, J. T. V. M. (2016). Child mental health in Sierra Leone: A survey and exploratory qualitative study. International Journal of Mental Health Systems, 10(1), 48. 
Open Access This chapter is licensed under the terms of the Creative Commons Attribution 4.0 International License (http://creativecommons.org/licenses/ by $/ 4.0 /$ ), which permits use, sharing, adaptation, distribution and reproduction in any medium or format, as long as you give appropriate credit to the original author(s) and the source, provide a link to the Creative Commons licence and indicate if changes were made.

The images or other third party material in this chapter are included in the chapter's Creative Commons licence, unless indicated otherwise in a credit line to the material. If material is not included in the chapter's Creative Commons licence and your intended use is not permitted by statutory regulation or exceeds the permitted use, you will need to obtain permission directly from the copyright holder.

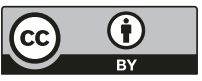

